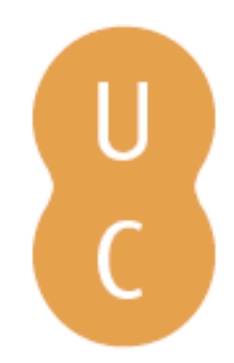

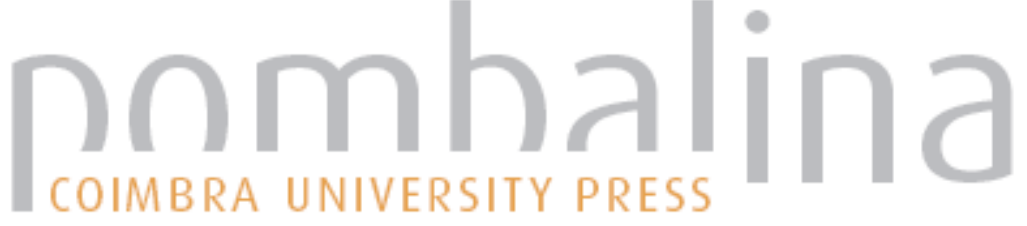

\section{Inimputabilidade em razão de alienação mental: um caso da época}

\author{
Autor(es): $\quad$ Antunes, Maria João; Costa, Francisco Santos
}

Publicado por: Imprensa da Universidade de Coimbra

URL

persistente: URI:http://hdl.handle.net/10316.2/32317

DOI: $\quad$ DOI:http://dx.doi.org/10.14195/978-989-26-0362-9_10

Accessed : $\quad$ 26-Apr-2023 13:55:14

A navegação consulta e descarregamento dos títulos inseridos nas Bibliotecas Digitais UC Digitalis, UC Pombalina e UC Impactum, pressupõem a aceitação plena e sem reservas dos Termos e Condições de Uso destas Bibliotecas Digitais, disponíveis em https://digitalis.uc.pt/pt-pt/termos.

Conforme exposto nos referidos Termos e Condições de Uso, o descarregamento de títulos de acesso restrito requer uma licença válida de autorização devendo o utilizador aceder ao(s) documento(s) a partir de um endereço de IP da instituição detentora da supramencionada licença.

Ao utilizador é apenas permitido o descarregamento para uso pessoal, pelo que o emprego do(s) título(s) descarregado(s) para outro fim, designadamente comercial, carece de autorização do respetivo autor ou editor da obra.

Na medida em que todas as obras da UC Digitalis se encontram protegidas pelo Código do Direito de Autor e Direitos Conexos e demais legislação aplicável, toda a cópia, parcial ou total, deste documento, nos casos em que é legalmente admitida, deverá conter ou fazer-se acompanhar por este aviso. 
Ana Leonar Pereira Jםão Rui Pita [ Coordenaçä̃ ]

\section{Miguel Bomberda e as singularidades de uma época}

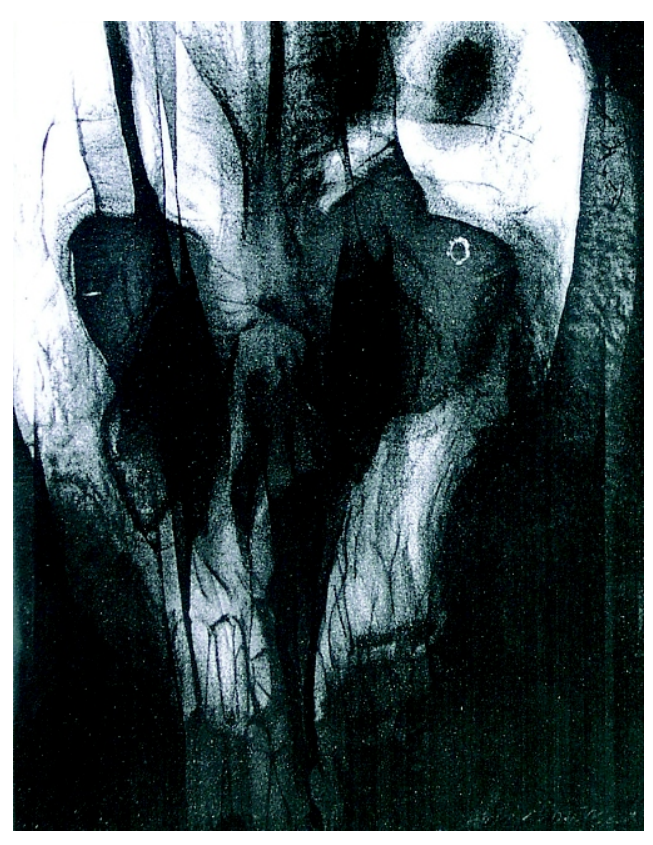


(Página deixada propositadamente em branco) 
Ana Leonor Pereira

João Rui Pita

(Coordenação)

\title{
FOLHA DE ROSTO
}

\author{
Miguel Bombarda (1851-1910)
}

a as singularidades de uma época 


\section{Coordenação Científica da Colecção Ciências e Culturas}

João Rui Pita e Ana Leonor Pereira

Os originais enviados são sujeitos a apreciação científica por referees

\section{Coordenação Editorial}

Maria João Padez Ferreira de Castro

\section{Edição}

Imprensa da Universidade de Coimbra

Email: impresauc@ci.uc.pt

URL: http://www.imp.uc.pt • Normas de publicação de colecções

Design

António Barros

Pré-Impressão

António Resende

Imprensa da Universidade de Coimbra

Capa

António Dantas. Sem título, 2002. Col. António Barros. Coimbra

Impressão e Acabamento

SerSilito • Maia

\section{ISBN}

978-989-8074-11-9

\section{Depósito Legal}

Obra publicada com a colaboração de:
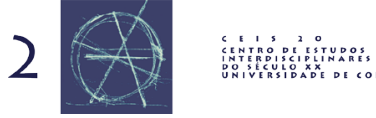

Obra publicada com o apoio de:

FCT Fundação para a Ciência e a Tecnologia

MINISTÉRIO DA CIÊNCIA, TECNOLOGIA E ENSINO SUPERIOR Portugal

Programa Operacional Ciência, Tecnologia, Inovação do Quadro Comunitário de Apoio III

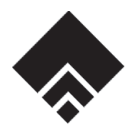

Fundaçāo Eng. António de Almeida

(C) Agosto 2006, Imprensa da Universidade de Coimbra 
Maria João Antunes* ; Francisco Santos Costa**

* Faculdade de Direito, Universidade de Coimbra, Portugal

** Hospital Sobral Cid, Coimbra, Portugal

\section{INIMPUTABILIDADE EM RAZĀO DE ALIENAÇĀO MENTAL: UM CASO DA ÉPOCA}

Inimputabilidade penal e alienação mental, só por si, são expressões a partir das quais pode ser feita uma aproximação a Miguel Bombarda, ao médico, ao alienista, ao cientista e ao republicano. Expressões que assumem outros contornos se as ligarmos ao nome Apparício Rebêllo dos Santos, aquele que é tido como o homem que assassinou Miguel Bombarda e que foi apelidado de «louco», de «doido», de «alienado»...

Atentando nos relatos da época e mesmo nos posteriores, podemos encontrar as seguintes expressões: "crime de homicídio praticado por um louco»; Bombarda «tomba varado por um paranóico»; o director do Hospital de Rilhafoles é vítima do "desvario de um louco»; foi vítima de um "atentado brutal de um louco»; «sucumbiu às mãos de um louco»; foi «assassinado por um doido»; foi atingido pela «bala assassina de um doente»; morreu «às mãos de um alienado».

Crime e loucura juntam-se neste caso, numa época de conflito entre os tribunais e os alienistas e entre estes e a opinião pública. De conflito, por ser ainda recente a evolução convergente da psiquiatria e do direito penal no sentido de os loucos serem declarados irresponsáveis pela prática dos seus crimes. Recente, porque só com o Código Penal de 1852 é que passou a ter força de lei a determinação segundo a qual «sómente podem ser criminosos os individuos que têem a necessaria intelligencia e liberdade» (artigo $22^{\circ}$ ) e, portanto, "não pódem ser criminosos os loucos de qualquer especie, excepto nos intervallos lucidos» (artigo 23으. Sendo que «nenhum acto é criminoso quando o seu auctor, no momento de o commetter, estava inteiramente privado da intelligencia do mal que commettia» (artigo 14º). Um conflito onde é referência obrigatória o caso do Alferes Marinho da Cruz - um conflito ocorrido no final da década de oitenta, do século XIX, protagonizado por Lombroso, Júlio de Mattos e António Maria Senna - e de que se foi servindo Miguel Bombarda para ilustrar decisōes judiciais avessas aos ensinamentos dos alienistas.

O caso do Tenente Apparício Rebêllo dos Santos surgiu-nos como um caso a partir do qual poderia ser investigada a forma como foi gerido o conflito reinante entre tribunais e alienistas e entre estes e a opinião pública, tanto mais quanto a vítima do homicídio em questão havia sido parte neste mesmo conflito, nele se revelando o interesse de Miguel Bombarda pela psiquiatria forense. Foram numerosas as intervençóes médico-forenses de Miguel Bombarda, defendendo a irresponsabilidade penal dos 
loucos, merecendo especial destaque o caso Josefa Greno, ocorrido no início do século $\mathrm{XX}$, em que a opinião pública exigia a condenação da pintora, pondo em dúvida a ciência dos peritos, que a davam por louca e penalmente irresponsável. Contribuiu de forma decisiva para a publicação da Lei de 3 de Abril de 1896, na qual se estabeleceu que devia proceder-se a exame médico-legal, quando fosse praticado algum crime ou delito que, pela sua natureza e circunstâncias especiais, ou pelas condições do agente, pudesse justificar a suspeita ou presunção de que este procedera em estado de alienação mental. Bateu-se pela construção do pavilhão de segurança no Hospital de Rilhafoles, não descurando o tema da «loucura penitenciária».

Decidimos analisar o processo crime correspondente ao caso do Tenente Apparício Rebêllo dos Santos, onde inevitavelmente depararíamos com a questão da inimputabilidade penal em razão de alienação mental. Procurámos dar seguimento à notícia publicada no Diário de Notícias, de 4 de Outubro de 1910: «Um louco, um oficial habilitado com o curso superior, assassinou ontem a tiros de pistola Browning o eminente professor e médico Dr. Bombarda. Os pormenores do fatal acontecimento (...) não fornecem nenhuma base definitiva para nos elucidar a que móbil obedeceu o criminoso praticando tão selvagem atentado. Pertence à Justiça e à Psiquiatria averiguar o que não nos é dado, neste labutar rápido do jornal, profundar».

Finalizada a investigação, nos locais onde provavelmente encontraríamos o processo judicial procurado - o Tribunal Militar de Lisboa, o Hospital Miguel Bombarda e a Casa de Saúde do Telhal - concluímos que o Tenente de Infantaria Apparício Rebêllo dos Santos, filho do Visconde de Proença, foi internado, em Março de 1909, aos 30 anos de idade, no Hospital de Rilhafoles, apesar de já anteriormente se terem evidenciado sinais da doença, nomeadamente por ocasião da sua passagem por Coimbra enquanto estudante. Padecia de alucinações de ouvido, ideias de perseguição sistematizadas e reacções violentas. O diagnóstico era o de paranóia primitiva e delírio de perseguição. Em Dezembro de 1909 teve alta, a pedido do pai, tendo-se deslocado a Paris para aí consultar dois clínicos da psiquiatria francesa. No dia 3 de Outubro de 1910 dirigiu-se ao gabinete do Director do Hospital de Rilhafoles e disparou sobre Miguel Bombarda. Em face do pedido para ser recebido, Bombarda não resistiu à tentação de confirmar os resultados clínicos obtidos em França. Dizia-se que Aparício tinha regressado completamente curado, mas Bombarda duvidava por não acreditar em milagres...

Verificámos, ainda, que em relatório do Conselho Médico-Legal, subscrito por Caetano Beirão, logo em 15 de Novembro de 1910, a Psiquiatria concluiu que Aparício era dotado dum fundo degenerativo. Foi de opinião que "Aparício Rebelo dos Santos se acha afectado de Paranóia primitiva com delírio de perseguição; que praticou o crime na pessoa de Miguel Bombarda debaixo da acção do seu delírio e é portanto irresponsável por ele; que deve continuar internado num manicómio, porque em liberdade pode ser prejudicial para si e para a sociedade». Constava ainda do relatório que "o alferes de infantaria é mais baixo do que alto - cabeça grande, sobretudo no sentido transversal, crânio achatado e 'platicefálico', um pouco calvo precocemente, cor terrosa e olhos encovados (...). Fala um pouco sobranceiramente e quási sempre com um sorriso sardónico, olhando mais para cima do que para as pessoas que o interrogam. Não só não estava arrependido, mas que havia de continuar até dar cabo do Hospital de Rilhafoles, porque é ele a desgraça de toda a sua vida. Foi para Paris; durante a jornada e mesmo ali, ouvia certas tolices que lhe dizia o Hospital que não o deixavam nunca». Por exemplo: não conseguiu aprender inglês - «a influência do 
Hospital era tal que a professora ensinava-lhe a pronunciar as palavras duma maneira e o Hospital dizia-lhe ao ouvido duma maneira diferente»; «nas ruas de Paris, Rilhafoles dizia-lhe que se atirasse para debaixo dum automóvel que passava; era então preciso grande esforço para não seguir o que ele lhe sugeria».

Da Justiça concluímos apenas que foi elaborado um "auto de corpo do delito». Não encontrámos quaisquer indícios no sentido de ter havido um processo crime, um julgamento ou uma decisão judicial final sobre o caso.

Aparício Rebelo dos Santos permaneceu no Hospital de Rilhafoles até Novembro de 1934, data em que foi transferido para a Casa de Saúde do Telhal, no cumprimento de decisão de transferência para esta instituição de todos os alienados militares. Morreu em Abril de 1943, nesta Casa de Saúde, onde vivia a seu pedido. Diogo Furtado, o médico militar que lhe prestava assistência, testemunhou que as ideias delirantes e os fenómenos alucinatórios foram-se esbatendo. A actividade delirante, já escassa quando deu entrada na Casa de Saúde do Telhal, «manifestada apenas por certas bizarrias da conduta e por certa tendência relacionadora, desapareceu mais tarde inteiramente, podendo, nos últimos anos da vida de Aparício, falar-se de cura completa, porquanto o processo psicótico lhe não produzira qualquer défice intelectual ou modificação da personalidade que denunciasse a anterior existência». O Tenente de infantaria recordava, então, os mínimos detalhes do delírio que vivera. Recordava, nomeadamente, as "vozes de Rilhafoles» que tanto o haviam atormentado.

Restaram-nos numerosas interrogações, ditadas pelo comportamento da Justiça penal e concretamente da Justiça penal militar, podendo, no entanto, concluir-se que neste caso foi o povo - não os tribunais em nome do povo, como seria esperado - quem administrou a justiça. O povo decidiu-se pela irresponsabilidade penal do réu, declarou-o inimputável em razão de alienação mental e decretou o seu recolhimento em hospital de alienados. Um desfecho que o Código Penal de 1886 passou a prever e que o Tenente Apparício aceitou de forma resignada: «os loucos, que, praticando o fato, forem isentos de responsabilidade criminal, serão entregues a suas famílias para os guardarem, ou recolhidos em hospital de alienados, se a mania fôr criminosa, ou se o seu estado o exigir para maior segurança» (artigo 47\%). Aceitou, apesar de este seu recolhimento em hospital de alienados ser de facto e não de direito.

Apesar de Miguel Bombarda ter sido vítima de um louco, de um louco muito religioso e conservador, que foi aluno dos padres da Companhia de Jesus, atributos que ainda levantaram algumas suspeitas a alguns revolucionários naquele momento histórico tão particular, o caso criminal Apparício Rebêllo dos Santos caiu num certo esquecimento. Se calhar, precisamente por se tratar de um antigo aluno dos padres da Companhia de Jesus, muito religioso e muito conservador, cujo crime ocorreu na antevéspera da implantação da República... Alguém que poderia sempre invocar os ensinamentos psiquiátrico-forenses de Miguel Bombarda, com o objectivo de ser declarado judicialmente irresponsável, do ponto de vista penal, em razão de alienação mental.

Os ensinamentos de Miguel Bombarda, mas também o testemunho da própria vítima: «Foi um doido! E diziam-me que estava curado! Veja lá você como elle estava curado!». Estas palavras, proferidas já no leito de morte, dirigiu-as ao amigo Pinto de Magalhães, com quem não pôde deixar de desabafar: «Morrer assim é estúpido!... E há tanto malandro que ia ficar radiante!... Esta noite, Magalhães podia eu morrer pela República!...». 


\section{BIBLIOGRAFIA}

AMADO, Silva ; BOMBARDA, Miguel ; VALLADARES, M. Diogo - «Actualidades. O caso Josepha Greno», A Medicina Contemporânea, Lisboa, XIX, 1910, pp. 341-344.

AMARAL, Almeida - "Miguel Bombarda e a assistência psiquiátrica», A Medicina Contemporânea, Lisboa, LXX, 1952, pp. 157-173.

BEIRÃO, Caetano - «Miguel Bombarda. II - O psychiatra», A Medicina Contemporânea, Lisboa, XXVIII, 1910, pp. 323-326.

BOMBARDA, Miguel - Liçôes sobre a epilepsia e as pseudo-epilepsias, Lisboa, Livraria de António Maria Pereira, 1896.

— «La folie pénitentiaire», Bulletin de l'Union Internationale de Droit Pénal, 1899, pp. 52-59.

CAMACHO, Brito - «Dr. Miguel Bombarda e Almirante Cândido dos Reis», Almanach d' A LUCTA, 1911, pp. 139-145.

CID, Sobral - O Professor Miguel Bombarda. A sua carreira e a sua obra de alienista, Faculdade de Medicina de Lisboa, MDCCCXXV-MCMXX.

COSTA, Celestino da - «Miguel Bombarda», Médicos Portugueses, Lisboa, I (4), 1927, pp. 121-142.

DERQUET, Luís - «Miguel Bombarda», Médicos Portugueses, Lisboa, I (4), 1927, pp. 143-149.

FERNANDES, Barahona - «Miguel Bombarda. Personalidade e posição doutrinal», A Medicina Contemporânea, Lisboa, LXX, 1952, pp. 139-155.

— «Exumação do caso da pintora Josefa GrenO», O Médico, 34, 1952, pp. 13-15.

— «Miguel Bombarda», O Médico, 41, 1952, pp. 169-172.

FRANCO, Evaristo - Glórias da Medicina Portuguesa, Lisboa.

FURTADO, Diogo - «Miguel Bombarda», sep. Jornal do Médico, XIX, 1952.

MAGALHĀES, Pinto de - "Miguel Bombarda. II - Notas d'um amigo - A autopsia», A Medicina Contemporânea, Lisboa, XXVIII, 1910, pp. 327-329.

SEABRA-DINIS, J. - "Miguel Bombarda, homem da sua época», A Medicina Contemporânea, Lisboa, LXX, 1952, pp. 185-196.

SOEIRO, Navarro - «Homenagem a Bombarda. Na Sessão da Sociedade de Neuropsiquiatria de 28 de Fevereiro de 1952», A Medicina Contemporânea, Lisboa, LXX, 1952, pp. 175-183.

Resumo - Na comunicação subordinada ao tema Inimputabilidade em razão de alienação mental: um caso da época, os autores pretendem estabelecer a ligação entre o conceito jurídico-penal de inimputabilidade e o conceito médico de alienação mental. Partem da análise de um caso da época, para desta forma poderem também dar conta da forma como se processavam as relaçôes entre os tribunais e os alienistas.

Abstract - The authors' lecture, which will approach the theme Not Guilty by the Reason of Mental Alienation: a case of the epoch, aims at establishing the link between the juridical-penal notion of NGRI's and the medical notion of mental alienation. They will take as a point of departure a case of the time in order to analyse the way relations between courts and alienists occurred. 
(Página deixada propositadamente em branco) 


\section{Colecção \\ Ciências e Culturas \\ Cuimbra 2006}

